This affinity is not always demonstrable to any appreciable degree in adrenal neoplasms with virilism, and may be absent even with hyperplasia. Nevertheless, it may well be of considerable significance, and one awaits with interest its ultimate evaluation. The section contains a considerable review of the literature, and some interesting speculation.

The fourth section describes the investigation of the urine of virile women for "male" comb-growth hormone. This has been established by other workers, but Patterson and Greenwood break new ground in determining that such urine contains what they describe as "free" male hormone, as distinct from "bound" male hormone. Such "free" hormone is said to be directly extractable by lipoid solvents without preliminary hydrolysis, and is absent from normal female urine, and present only in small quantities in normal male urine. It apparently disappeared after unilateral adrenalectomy, but in most instances the urine was examined in the immediate pre-operative period, which may obviate such results. However, in a few cases examined three months later such hormone was almost or completely absent, an important finding of apparent significance. Marrian and Butler have isolated from the urine of virile women a new substance pregnane 3-17-20 triol $\left(\mathrm{C}_{21} \mathrm{H}_{36} \mathrm{O}_{3}\right)$, and they describe their methods and compare their important results with the work of other biochemists in this field.

Sir Walter Langdon-Brown contributes a valuable foreword, with his usual sagacity and balanced judgment.

\section{POULSSON'S TEXTBOOK OF PHARMACOLOGY AND THERAPEUTICS.}

Second English Edition thoroughly revised by Stanley Alstead, M.D. Liverp., M.R.C.P. Lond., Pollok Lecturer in Materia Medica and Therapeutics in the University of Glasgow. London. William Heinemann (Medical Books) Ltd. 1938. Price 25s. net.

The revision of Poulsson's classical work has been ably carried through bv Dr. Alstead. As in the previous edition attention has been concentrated on therapeutic aspects of the subject, although ample consideration has been given to general pharmacology.
It is obvious from a perusal of various chapters that great care has been paid to the incorporation of modern views on the actions of drugs. Always, however, attention has been focused on the fact that the book is intended for practitioners of medicine. To a few minor points exception might be taken: thus it is stated that desiccated parathyroid gland may be given by mouth, a method of administration, which is not likely to yield therapeutic results.

The book makes easy and interesting reading and should prove of considerable value not only to the student studying for professional examinations, but even more to the physician who must keep himself abreast with modern developments in pharmacology. We wish the book every success and are very hopeful that it will retain the esteem and popularity which was accorded the first edition.

\section{THE ESSENTIALS OF PHARMACOLOGY, MATERIA MEDICA AND THERAPEUTICS FOR MEDICAL STUDENTS.}

By D. M. MacDonald, M.D., F.R.C.P.E London. Henry Kimpton. 1938. Price 7s. 6d. net.

This volume, of somewhat similar scope to the previous one, differs in the alphabetical arrangement adopted and the special feature made of the prescribing notes. All the relevant facts are given.

\section{A CONCISE PHARMACOLOGY.}

By F. G. Hobart, Ph.C. and G. Melton, M.D., M.R.C.P. With a foreword by Adolphe Abrahams, O.B.E., M.A., M.D., F.R.C.P. London. Leonard Hill Limited. 1937. Price 7s. 6d.

In this little book is presented in concise fashion the pharmacology of the more important drugs used in Britain and the U.S.A. The volume is intended for students of medicine since discussion is limited to pharmacological actions of importance in therapeutics. While we feel that the subject of pharmacology is of sufficient importance to require a more intimate discussion of general ? principles of drug action and a more detailed account of the effects of many drugs from 